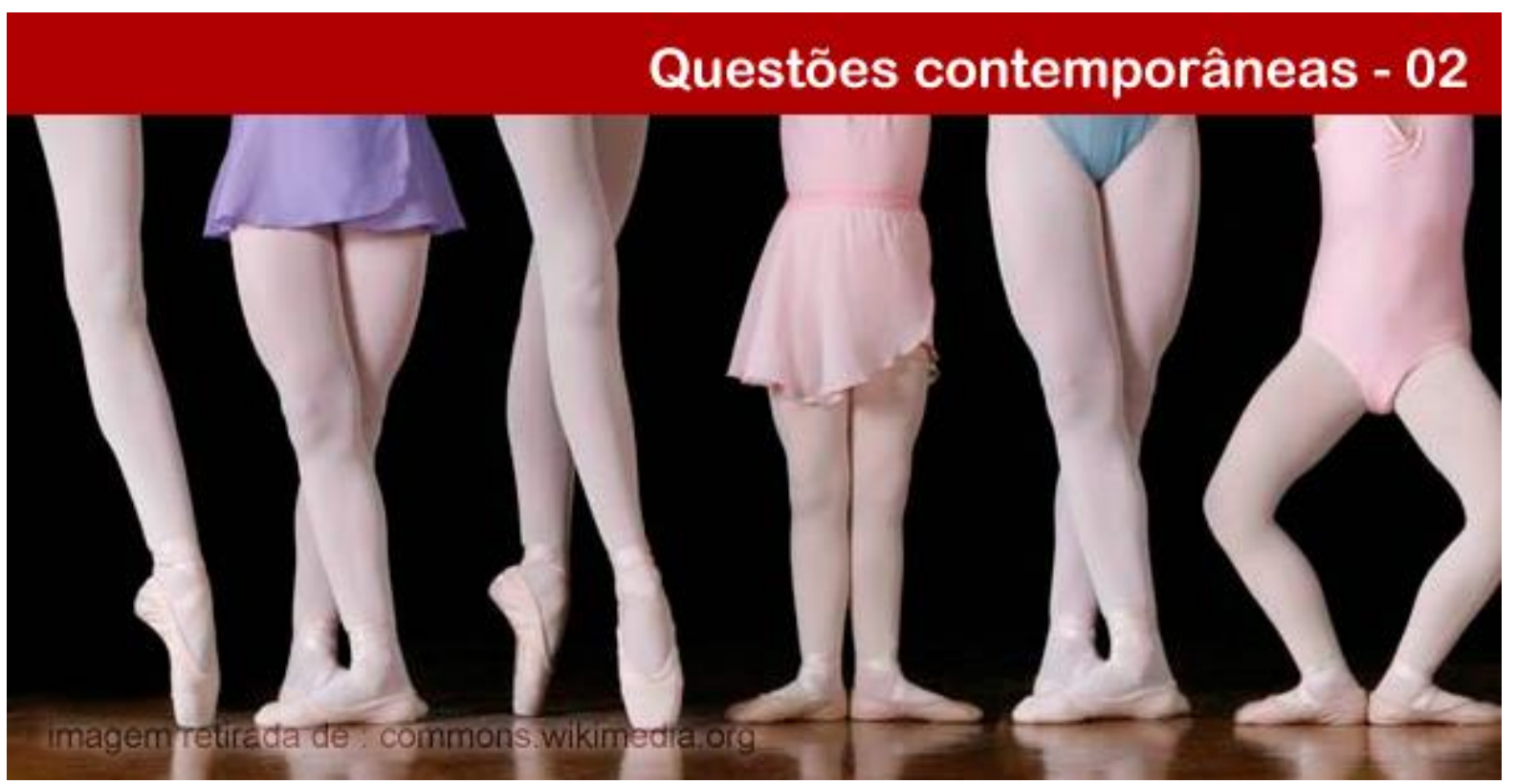

\title{
ENUNCIADO-DANÇADO: APPROACH BAKHTINIANO SOBRE O BALLET CLÁSSICO NA ESCOLA ${ }^{1}$
}

Jean Carlos Gonçalves

Ator/Performer e Diretor de Teatro. Professor Adjunto da Universidade Federal do Paraná (UFPR). Atua na Graduação em Produção Cênica e nos Programas de Pós-Graduação em Educação - Mestrado Acadêmico e Doutorado (PPGE/UFPR) - e Educação: Teoria e Prática de Ensino - Mestrado Profissional (PPGE:TPEn). Coordenador do grupo de pesquisa EliTe/CNPq/UFPR - Laboratório de estudos em Educação, Linguagem e Teatro.E-mail: jeancarllos@ufpr.br.

\section{Thais Castilho Candido}

Bailarina, coreógrafa e professora de dança. Mestre em Educação pelo Programa de Pós-Graduação em Educação da Universidade Federal do Paraná (PPGE/UFPR). Bacharel e Licenciada em Dança pela Faculdade de Artes do Paraná - UNESPAR, Campus II-Curitiba. Integra o grupo de pesquisa EliTe/CNPq/UFPR - Laboratório de estudos em Educação, Linguagem e Teatro. E-mail: tahcastilho@hotmail.com.

Resumo: Esse texto tem como objetivo geral refletir sobre a relação entre ballet clássico e educação, investigando possibilidades de trabalho prático a partir do binômio enunciado-dançado no contexto escolar. A abordagem teórica recorre a autores que discutem a dança na escola e a contribuições dos estudos da linguagem, especialmente os desenvolvidos por Bakhtin e o Círculo. A partir da proposição da noção de enunciadodançado, o artigo explora aproximações e fronteiras entre ballet clássico e autoria, bem como as reverberações desse diálogo para a esfera educacional.

Palavras-chave: Ballet clássico. Educação. Bakhtin e o Círculo.

\section{ENUNCIATION-DANCING: BAKHTINIAN APPROACH ON THE CLASSICAL BALLET IN SCHOOL}

\footnotetext{
${ }^{1}$ O presente trabalho foi realizado com o apoio do CNPq - Conselho Nacional de Desenvolvimento Científico e Tecnológico e da CAPES - Coordenação de Aperfeiçoamento de Pessoal de Ensino Superior.
}

\section{POLÊM!CA LABORÊ (t)}

Polêmica - Revista Eletrônica da Uerj - Rua São Francisco Xavier, 524, $1^{\circ}$ andar

bloco D, sl.1001 • Tels.: +55 21 2334-4088/4087 • http://www.e-publicacoes.uerj.br/index.php/polemica/index http://www.labore.uerj.br • laboreuerj@yahoo.com.br 
Abstract: This text has the general objective to reflect on the relationship between classical ballet and education, investigating practical work possibilities from the binomial enunciation-dancing in the school context. The theoretical approach uses authors who discuss dance in school and the contributions of language studies, especially those developed by Bakhtin and the Circle. Based on the proposal of the concept of enunciationdancing, the article explores approaches and boundaries between classical ballet and authorship, and the reverberations of this dialogue for the educational sphere.

Keywords: Classical ballet. Education. Bakhtin and the Circle.

\section{Ballet Clássico e Educação: uma introdução}

As palavras dança e educação remetem a dois campos semânticos diferenciados, que se relacionam, no mínimo, a duas áreas de conhecimento, e até mesmo a duas vertentes de atuação profissional - dois modos paralelos de ser e estar no mundo que, quando estudados ou vivenciados separadamente, delimitam formas de pensar e de agir que podem ser notadamente distintas, como, também, muito semelhantes. Nesse trabalho, dança e educação encontram uma discussão entrelaçada, enviesada, que delimita um campo híbrido e, de acordo com o pensamento de Marques (2010b), uma vez hibridizados, esses dois campos estão ligados, mas não necessariamente misturados ou fundidos, pois, enquanto área de conhecimento, eles se cruzam dialogicamente, em justaposição, formando uma dança que se multiplica em inúmeros sentidos, compreensões e possibilidades de atuação.

O trabalho com a dança no ambiente escolar tem a capacidade de torná-lo um lugar diferenciado de aprendizagem, que possibilita a criação, a reflexão e a conscientização; um lugar potente para o desenvolvimento integral dos alunos. Por meio da dança é possível formar educandos conscientes de si e do ambiente que os cerca, visto que "corpos que se conhecem têm grandes possibilidades de estabelecer diálogos diferenciados com os outros, com o meio e com o mundo" (MARQUES, 2010a, p. 206).

Faz-se interessante ressaltar que há várias nomenclaturas para designar a dança, inserida como linguagem na disciplina de Arte: dança criativa, dança educativa, dançaeducação; como se fosse possível ou mesmo necessário desenvolver uma estratégia para que a aula de dança pudesse ser reconhecida como uma forma de fazer e ensinar dança, que pudesse vislumbrar a chance de criação e expressão do corpo na escola. Vale lembrar que no contexto educacional, por muito tempo, trabalhava-se apenas com a reprodução de gestos e sequências de passos de uma determinada técnica de dança, como o ballet clássico, o hip hop, jazz, dentre outras (STRAZZACAPPA, 2001) sem, no entanto, possibilitar ao educando uma construção

\section{POLÊM!CA $\mid$ LABORE}


de conhecimento que estivesse relacionada a qualquer indício de autoria ou mesmo de autonomia.

O ballet clássico carrega princípios da Europa renascentista. As aulas de ballet são carregadas de ritos específicos e de uma rigidez bastante conhecida, que implica em uma mostra de sequências de movimentos pelo professor, a partir do registro de poses e gestos préestabelecidos e de porte elegante. Em seguida os alunos se lançam à reprodução dos movimentos, em um processo de repetição que deve buscar a excelência. É possível questionar, desse modo, qual a efetividade de vivências com o ballet clássico na escola, mais especificamente no contexto da disciplina de arte, se o ensino da dança requer o contato com experiências corporais diversificadas que proporcionem a reflexão sobre si mesmo, a criticidade, a capacidade de comunicação com o outro e a ampliação da visão de mundo. $\mathrm{O}$ ballet clássico poderia, em algum momento, descolar-se de seu rigor e se configurar enquanto um projeto discursivo harmônico com os pressupostos de uma educação emancipadora?

Malanga (1985) destaca que a técnica clássica norteou-se pela busca de leveza, da agilidade, da postura ereta, alongamentos e o amplo equilíbrio, na qual o bailarino treina para conquistar o domínio do corpo, de modo a poder utilizá-lo de forma consciente nos passos dessa dança. Lima (1995), por sua vez, afirma que o Ballet é uma prática complexa e extremamente técnica, a qual exige de seu praticante um desempenho de atleta. Um curso tradicional de ballet clássico necessita de música clássica, espaço físico com espelhos, barras e chão preparado para amortecer impactos, além de roupas específicas. As aulas são iniciadas na barra, que serve de apoio para execução de uma série de exercícios que darão aos bailarinos o entendimento dos movimentos dessa dança, a postura, a seguridade. Após o aquecimento da musculatura, começam os exercícios no centro da sala, sequências de passos em frente ao espelho, baseados nas atividades já feitas na barra para treinar a habilidade - bem como saltos e giros. Na parte final da aula, realizam-se movimentos de braços, cabeça e dorso em reverências, caracterizando uma despedida (COSENTINO, 1985).

A dança na escola, no entanto, não tem por objetivo priorizar a execução de movimentos dentro de uma técnica específica, não elege um único padrão estético, e não deveria desenvolver aulas com um roteiro fixo de sequências como acontece no rito do ballet. No ambiente escolar, o movimento deve ser compreendido como uma forma pessoal de expressão, de comunicação, portanto, não deve considerar apenas a graciosidade, a beleza das

\section{POLÊM!CA $\mid$ LABORE}


linhas corporais e a leveza de passos pré-estabelecidos, e sim a liberdade que possibilita ao educando se comunicar e encontrar a autossuficiência no próprio corpo, objetivando a formação de um cidadão crítico, participativo e responsável. A criança deve viver experiências variadas com o corpo em movimento: rolar, sujar as mãos, escorregar, cair, gritar, entre outras, o que contribui para o desenvolvimento dos músculos, da curiosidade e da audácia (SCARPATO, 2001).

Através de experiências criativas com a dança na escola, o aluno deve ser convidado a dançar, respeitando sua movimentação pessoal e seus gestos cotidianos, a apreciar obras de dança e a conhecer as dimensões sociopolítico-culturais da dança. $\mathrm{O}$ educando deve ser apresentado à Coreologia - à lógica oculta da dança, para que ele compreenda o que, o como, o onde e com o que o movimento acontece, de modo que possa tomar consciência de si e do ambiente que o cerca, identificando os espaços e os modos onde o corpo tem possibilidade de atuar (BRASIL, 1998).

Nessa perspectiva, o ballet clássico, uma linguagem que surgiu no Renascimento e abriga uma técnica requintada a ser treinada e aprimorada rumo à exuberância artística, teria sua gênesis diferenciada da dança que foi pensada para a escola. Todavia, vale ressaltar que, de acordo com Strazzacappa (2001), o entendimento sobre dança não é universal. Cada local, cada profissional, olha para a dança e suas funções de modo diferenciado, o que faz com que o entendimento sobre dança se atualize constantemente. Para a autora, as danças típicas provenientes de países específicos (como a dança do ventre, o sapateado e as danças de rua), por exemplo, atualmente, poderiam ser concebidas como expressões culturais que sofrem ramificações tanto para o campo da recreação, como para a área da dança profissional, visto que elas já saíram dos seus contextos populares específicos para invadir as academias, as ruas e os teatros. Nesse viés, o ballet clássico, cuja origem é uma formação técnica de status profissional, pode, hoje, ocupar espaços de recreação dentro de academias e outros contextos, pois, muitas pessoas buscam essa técnica como complemento da educação corporal ou como momento de lazer.

Seguindo o pensamento de Strazzacappa (2001), verifica-se que, independentemente da gênesis e dos objetivos para com determinados tipos de dança, é muito tênue a linha que os separa. Todas as motivações de dança estão inter-relacionadas: as manifestações culturais podem ser trabalhadas de modo amador, as técnicas profissionais podem desenvolver aspectos

\section{POLÊM!CA LABORE}


terapêuticos, além de todas elas carregarem aspectos criativos e educativos. Entende-se, dessa maneira, que esse diagrama não é fixo, cristalizado, e que cada instituição de ensino deve pensar maneiras diferenciadas de se trabalhar com a dança. Nessa direção, compreende-se, também, que o ballet clássico não seria totalmente apartado e distante de uma dança expressiva idealizada para o ambiente escolar, uma vez que existe uma linha tênue que as distingue, e que as mantém inter-relacionadas.

Por isso, em meio às constantes bifurcações e transformações das diferentes motivações de dança, Strazzacappa (2001) ainda alerta que deve-se tomar cuidado ao adjetivar uma dança, ao nomear uma determinada coreografia ou alguma aula, principalmente nos trabalhos práticos com a dança em escolas regulares. É possível identificar que, numa tentativa de trazer organização e de apresentar um referencial filosófico para um determinado tipo de dança, é comum nomeá-la e dá-la um rótulo, o que pode gerar a cristalização da estética e das maneiras de pensar, ensinar e realizar dança na disciplina de Arte.

Nota-se que, para Strazzacappa (2010), todo o tipo de dança possui conhecimentos e pode levar à transformação de seus dançantes. Ou seja, não é somente a dança realizada na escola que pode ser "criativa" ou "educar" levando os alunos à reflexão e criticidade, mas também o ballet clássico e qualquer outra linguagem. Afinal, "não é a Dança em si que porta o ser 'criativa' e sim o professor, instrutor, mediador, ou seja, o adulto que estará junto à criança em seu processo de exploração, interação, iniciação à Dança" (STRAZZACAPPA, 2010, p. 45).

Marques (1999) também destaca tal questionamento sobre os termos diferenciados, e ao mesmo tempo semelhantes, para referenciar à dança em contexto educacional, destinada às crianças e aos jovens das escolas regulares. Para a pesquisadora, todas as danças são educativas se forem ensinadas de maneira que os alunos possam compreender, sentir, verbalizar, contextualizar e apreciar aquilo que estão dançando. Por isso, seria interessante falar que se ensina, simplesmente, "dança" nas escolas.

Marques (2010b) aponta que muitos professores de Arte na escola, seja por comodismo, ou por ingenuidade, ainda fornecem atividades esparsas de dança, como aulas com repetição de sequências de movimentos pré-estabelecidos, sem aprofundamento ou discussão, e ensaios de coreografias folclóricas para a apresentação em festividades, desprovidas de processos criativos. Para a pesquisadora, esses arte-educadores apenas

\section{POLÊM!CA $\mid$ LABORE}


desenvolvem um breve contato de seus alunos com a dança, ao invés de estabelecerem uma relação entre eles e os saberes dessa área do conhecimento. A visão de Marques (2010a; 2010b) se aproxima de Strazzacappa (2010), porque a autora também argumenta que não é qualquer aula ou qualquer ação em dança que desenvolverá seu potencial transformador. “As propostas metodológicas, os caminhos e as trajetórias de ensino - o 'como' se ensina e se aprende - são determinantes nos processos de educação e transformação." (MARQUES, 2010a, p. 138). Os pequenos contatos dos alunos com os saberes da dança não os permitem distinguir órbitas dentro e fora de si, já o conjunto de relações significativas estabelecidas durante as aulas, ao contrário, leva à transcendência, à possibilidade de vislumbrar horizontes distintos. É aí que o encontro da dança com a educação pode estabelecer relações entre essas duas áreas, possibilitando ao aluno impregnar de sentidos suas ações e seu cotidiano (MARQUES, 2010b).

Nota-se, então, que a concepção de ballet clássico, compreendida como técnica de dança que exige exuberância física e uma performance profissional, com origem, objetivos e o desenvolvimento bastante distantes conceitualmente da origem, dos objetivos e do desenvolvimento da dança pensada para a escola, precisa ser ressignificada. Não teria sentido, por exemplo, levar uma aula tradicional de ballet para a disciplina de Arte, com exercícios fixos de barra e centro, com a intenção de que os educandos alcançassem a virtuose e a excelência em seus passos codificados, tornando-se exímios bailarinos clássicos. Levando em consideração, então, as expectativas para a dança na escola, não seria coerente um ensino de ballet no ambiente escolar, tal como executado em escolas de dança ou companhias profissionais, tendo como o principal objetivo o aprimoramento técnico dos alunos. Afinal, por mais que o ballet também carregue o potencial educativo e leve à construção do conhecimento em arte, a dança no contexto educacional não visa estabelecer padrões técnicos e estéticos, ou manter um roteiro de sequências de movimentos a serem copiadas pelos alunos. As escolas raramente dispõem, por exemplo, de espaço físico preparado para o ballet, ou fornecem aos educandos vestimentas apropriadas para sua realização. Até mesmo os professores de Arte teriam dificuldade para lecionar essa técnica de dança, tanto aqueles formados em licenciaturas de Teatro, Música ou Artes Visuais, como também os educadores licenciados em Dança que não se aprofundaram nessa linguagem específica.

\section{POLÊM!CA $\mid$ LABORE}


Entretanto, a dança no contexto educacional e o ballet clássico podem até parecer, em um primeiro momento, duas ações artísticas contraditórias, duas áreas distintas de conhecimento, porém, ao aprofundar a ideia de Strazzacappa (2001), observa-se que, na realidade, ambas podem ser ramificadas e bifurcadas entre as diversas motivações em dança, gerando novos modos de dançar, com diversos objetivos e outros meios de desenvolvimento fenômeno ao qual nem a dança de cunho expressivo nem o ballet clássico estão imunes.

Seria possível, então, uma prática educativa em arte que, além de proporcionar um breve contato com o ballet clássico, permitisse que os alunos estabelecessem relações de vivência e experimentação significativas, tal como propõe Marques (2010b)? Seria possível estabelecer relações dialógicas entre a educação e o ballet clássico? De que maneira seria possível instigar os educandos a alcançar a liberdade, a criação, a comunicação e a autoria no trabalho com o ballet clássico no contexto da disciplina Arte na escola? Sem a pretensão de responder a essas questões, a próxima seção discute algumas dessas inquietações, buscando, por meio de articulações com a teoria dialógica de Bakhtin e o Círculo, apresentar a noção de enunciado-dançado: uma abordagem teórico-prática para a compreensão da relação entre ballet clássico e educação.

\section{Enunciado-dançado: o ballet clássico em perspectiva dialógica}

Ao dançar, o corpo/indivíduo carrega a capacidade de se comunicar consigo e com os outros, expressando sua forma de ser e estar no mundo, suas impressões, suas ideias, e até mesmo seus sentimentos, falando sobre si, sobre o que vê, sobre o que pensa, sobre o que se move dentro e fora dele. Muitas são as teorias da área da dança que abrangem a capacidade comunicacional do corpo, apontando sua possibilidade de produzir discursos enquanto se movimenta. Tal como a Corpomídia, de Katz e Greiner (2004; 2003 apud SETENTA, 2008), que apresenta um corpo pensante em contínua relação com o ambiente, tornando-se uma mídia de si mesmo; e também o Fazer-Dizer, de Setenta (2008).

O corpo discursa. E na escola o aluno é convidado a sentir, imaginar, interagir, expressar-se enquanto ser que dança, porque a dança é uma forma de conhecimento que envolve a intuição, a emoção, a imaginação e a capacidade de comunicação. A criação artística dos alunos em sala de aula se dá pela interação com os colegas, suas obras e as obras de grandes artistas, "mediante a elaboração de idéias, sensações, hipóteses e esquemas

\section{POLÊM!CA $\mid$ LABORE}


pessoais que o aluno vai estruturando e transformando, ao interagir com os diversos conteúdos de Arte manifestados nesse processo dialógico" (BRASIL, 1998, p. 19). Os corpos/alunos dialogam com suas vivências, expectativas, projetos e suas escolhas de vida, para que eles possam se comunicar, expressar, imaginar e, assim, atribuir sentidos às suas experiências.

Não obstante, falar em relações dialógicas, interação e atribuição de sentidos nessa pesquisa é falar, também, em Bakhtin e o Círculo². Por compreender corpo e o indivíduo em uma única instância, o movimento corporal pode ser observado, pelas lentes bakhtinianas, como um enunciado. Para construir o diálogo entre o ballet e a educação via Bakhtin, faz-se importante compreender que, para o filósofo, é na relação sócio-histórica e na relação dialógica entre sujeitos que está o cerne do processo que constitui o discurso. Bakhtin (2003) defende a natureza social e não individual da linguagem, no qual o processo de construção discursiva do sujeito se dá pela interação entre os participantes de uma situação de enunciação.

Observa-se que, na perspectiva bakhtiniana, um sujeito não constitui uma frase/oração e promove seu discurso apenas somando palavras ou colando expressões de modo fracionado e fragmentado. As palavras, sem o crivo da interação, são consideradas, na perspectiva bakhtiniana, soltas, vazias, não pertencentes a ninguém. As palavras só terão força quando um sujeito enunciá-las, e ele a enunciará contaminado pelos valores culturais que o constituem, preenchendo-as com sentidos, significados e significações. O homem é social, e a palavra, nessa linha de pensamento, é considerada como um fenômeno ideológico.

Lembrar a questão do sentido e seus signos ideológicos é essencial para compreender o fenômeno enunciativo-discursivo. Os sentidos se constituem pelas interações sociais e comunicacionais. Nos estudos de Bakhtin e o Círculo, ideologia é uma palavra usada para designar o universo dos produtos do "espírito humano", ou seja, uma cultura imaterial, que abrange as formas da consciência social e todo o seu universo: ética, arte, ciência, religião, filosofia ou política. O produto ideológico surge de uma realidade social, e ao dar-lhe

\footnotetext{
${ }^{2}$ Os estudos bakhtinianos, ou o pensamento bakhtiniano, é o conjunto de formulações teóricas advindas do chamado Círculo de Bakhtin. Embora existam diferentes atribuições ao termo, por parte de alguns pesquisadores, esse texto não trará uma explanação explicativa e histórica, mas utilizará a expressão "Bakhtin e o Círculo" para se referir ao conjunto da obra que traz ideias produzidas por intelectuais russos, desde a segunda década do século XX, entre os quais Mikhail Bakhtin (1895-1975), Valentin N. Volóchinov (1895-1936) e Pável N. Medviédev (1891-1938).
}

\section{POLÊM!CA $\mid$ LABORE}


significado, forma-se um signo: um objeto ou uma palavra, a partir da interação entre os sujeitos, passam a se revestir de sentido, são dotados de simbolismo, passam a refletir realidades distintas (BRAIT, 2005).

O domínio ideológico coincide com o domínio dos signos, porque são mutuamente correspondentes. Onde o signo está, encontra-se também o seu caráter ideológico, e tudo que é ideológico acaba possuindo valor semiótico. A própria consciência individual, por sua vez, forma-se com base no sistema semiótico de encontros de signos, impregnando-se de ideologia, pois emerge através da interação social, na qual um determinado grupo socialmente organizado possui um sistema de signos inteligível entre seus participantes (BAKHTIN, VOLOSHINOV, 2010). A consciência individual se configura, assim, como um processo social e ideológico, que adquire forma nos signos criados pelas relações sociais. Os signos acabam sendo o alimento dessa consciência individual, a matéria para seu crescimento, e ela acaba refletindo sua própria lógica e suas leis. Caso a consciência seja privada de seu conteúdo semiótico e ideológico, não sobrará nada (BAKHTIN, VOLOSCHINOV, 2010).

Na perspectiva bakhtiniana, o dialogismo é o fundamento da linguagem, visto que a vida é dialógica por natureza. De acordo com Sobral (2009), vinculado, indissoluvelmente, à interação, o dialogismo é a base do processo de produção dos discursos, no qual o sujeito que fala leva o outro em consideração e olha seu interlocutor como parceiro ativo para constituir seu enunciado. Amorim (2009; 2010) salienta que dialogia é o caráter da interação enquanto categoria básica da concepção de linguagem, visto que toda enunciação faz parte de um processo de comunicação interminável com o outro, com o mundo. Bakhtin pressupõe a existência do outro, reconhecido pelo "Eu" como outro que não eu; e a relação dialógica é o que possibilita a interação entre o eu e o outro.

Para Bakhtin, um locutor não enuncia algo cujo significado tenha origem em si mesmo, ou que possa surgir no tempo presente, no exato instante da comunicação - o sujeito não é a origem de seu dizer. Ou seja, os enunciados não são palavras e significações originárias do momento da enunciação; eles já fazem parte de um continuum - uma contínua rede de interação entre Eu e o(s) outros(s). Assim, quando alguém fala, não está falando sobre algo totalmente novo, único ou estritamente particular, que tenha a capacidade de romper o silêncio do mundo; todo enunciado está imerso na cadeia infinita da comunicação discursiva (BAKHTIN, 2003).

\section{POLÊM!CA $\mid$ LABORE}


Bakhtin também discute, dessa maneira, a alteridade constitutiva dos sujeitos. Segundo Amorim (2009), o drama individual da existência humana, a questão da identidade, é, também, o marco das obras de Bakhtin, que vê o outro como uma referência, o outro como a condição do Eu. A alteridade e o próprio princípio do dialogismo implicam no encontro das vozes em um espaço e um tempo social e historicamente constituídos.

No pensamento bakhtiniano, a alteridade é uma relação constitutiva, imanente das relações sociais e presente nas mais variadas manifestações de linguagem aí produzidas e que se concretiza na multiplicidade de vozes que se entrecruzam nas situações de discursividade (BRAIT, 2005). A interação entre eu-outro-outros possibilita a ampliação dos horizontes dos sujeitos, no desdobramento dos lugares enunciativos e na multiplicação de vozes. $O$ dialogismo e a alteridade, nessa direção, acabam por definir o ser humano, visto que "é impossível pensar no homem, fora das relações que o ligam ao outro" (BARROS, 2001, p. 30).

Seguindo essa linha de pensamento, observa-se que não existe uma autoria estritamente individual de enunciados e que a palavra não pertence somente àquele que a enuncia, não é exclusiva a ele, não veio ao mundo apenas por ele, não nasceu no momento em que o falante a enunciou, pois, faz parte da infinita cadeia de vozes de um espaço-tempo; não existe apenas um Eu, existe, na realidade, um Nós. O ser humano não existe para si, senão na medida em que é para os outros, e essa relação estabelecida pela enunciação constitui tanto os sujeitos quanto os sentidos de seus discursos (BAKHTIN, 2010).

Entende-se, dessa maneira, que para construir um enunciado, é preciso entrar em contato com a infinita cadeia de vozes já existente no mundo, e as palavras passam a ser preenchidas por sentidos advindos do mundo social. Por isso, os enunciados particulares de um sujeito não são tão particulares assim; tratam-se, na realidade, de um conjunto de vozes, de uma pluralidade de vozes, formado pela dialógica constituição do sujeito na sociedade.

Então, partindo do pressuposto que o movimento é o enunciado do corpo, e levando em consideração as noções de enunciado, dialogismo e alteridade na perspectiva bakhtiniana, é possível entender que o movimento individual é constituído a partir de uma rede de relações dialógicas com os movimentos de outros, a partir de uma contínua cadeia de movimentos já existentes no mundo. Ou seja, ao entender que não existe apenas um Eu, e sim um Nós, vislumbra-se que, para se mover e construir uma dança, o sujeito se apropria de gestos

\section{POLÊM!CA $\mid$ LABORE}


preenchidos de sentidos, advindos da sociedade que o circunda. Movimentos esses que apenas parecem ser exclusivamente seus, pertencentes somente a ele, porém, na realidade, fazem parte dos ecos de movimentos, ecos que o constituem enquanto sujeito, enquanto ser partícipe de situações de interação.

Por meio da perspectiva bakhtiniana é possível afirmar que o movimento nunca não é um gesto inaugural, ou seja, não surge de repente. Trata-se de um enunciado impregnado de sentidos, da fala do corpo realizada via alteridade, pois, ao dançar, o corpo também se comunica a partir de cadeias dialógicas infinitas. Enquanto o corpo se move, ele também (se) comunica, (se) expressa, (se) interage. Para construir sua dança, o corpo dialoga com outros corpos, com outros movimentos, e realiza uma Arte impregnada de sentidos - signos e significações advindos da sociedade que o constitui, e que por ele também é constituído. O que parece um simples movimento enunciado por um único sujeito, trata-se, na verdade, de uma pluralidade de movimentos.

Assim, por compreender o próprio movimento como enunciado, esse texto propõe um olhar para o ballet clássico a partir da noção de enunciado-dançado. $\mathrm{O}$ corpo não fala e se move em momentos separados - não se move para falar, nem se fala para mover, uma atividade não ocorre antes ou depois da outra, e sim agem juntas. Enquanto dança, o corpo também fala, produz sentidos, constitui textos sígnicos passíveis de leituras; por isso o hífen organiza melhor a presente ideia, formando um binômio: enunciado-dançado.

Para entender essa proposta, é relevante destacar que, na perspectiva bakhtiniana, o enunciado se aproxima atualmente da concepção de texto, o qual é considerado tanto como um objeto de significação, um tecido organizado de informações, e também como objeto de comunicação de uma cultura, cujo sentido depende do contexto histórico e social. O texto, como enunciado concreto, recupera estatuto pleno de objeto discursivo, social e histórico (BARROS, 2011). Em Bakhtin, o texto se configura como a possibilidade da construção de enunciados concretos, que pode ocorrer em diversas formas de expressão, visto que todo "fenômeno que funciona como signo ideológico tem uma encarnação material, seja como som, como massa física, como cor, como movimento do corpo ou como outra coisa qualquer" (BAKHTIN, VOLOSCHINOV, 2010, p. 33).

\section{Considerações para uma provisória conclusão}

\section{POLÊM!CA $\mid$ LABORE}


Pensar o ballet clássico na escola a partir a ideia de enunciado-dançado é abrir possibilidades para a relação com a autoria. Bakhtin e o Círculo designam por autor não apenas um autor de obras artísticas, mas também o autor de enunciados. O Círculo também considera os atos de discurso como parte do conjunto dos atos humanos em geral (SOBRAL, 2009). Com isso, entende-se que as coreografias de ballet clássico, produzidas pelos coreógrafos dos séculos passados, os quais se configuram como primeiros autores dos espetáculos em um determinado tempo e espaço, quando produzidas em outras esferas e tempos, redimensionam a relação com a irrepetibilidade, podendo se constituir enquanto Enunciados-Dançados. Estes são carregados de vozes que fazem parte das contínuas cadeias dialógicas, que os preenchem de sentidos e os permitem ser ressignificados em qualquer espaço-tempo.

Os passos do Ballet, tal como as palavras, são soltos, não pertencem a ninguém, e só terão força quando forem realizados por um aluno-bailarino. A partir do pensamento bakhtiniano, é possível afirmar que o enunciado-dançado é a realização de um passo-palavra em dança, compreendido como ato enunciativo-discursivo e, por sua própria natureza comunicativa, implica autoria, irrepetibilidade e singularidade. Essas características dão à dança o status de texto, que ganha, pelos movimentos de um corpo dançante, novos sentidos, sempre em conexão com realidades específicas e distintas. Machado (2005), apoiando-se na perspectiva bakhtiniana, aproxima a noção de texto a uma reorganização necessária da concepção de signo ideológico: "Como signo, o texto se realiza no cruzamento de sujeitos discursivos ao mobilizar significados gerados no evento comunicativo" (p. 54). Compreendese, então, que a aproximação entre ballet clássico e educação necessita, também, de reconfigurações que possibilitem ao aluno-bailarino um contato com a dança que, mesmo de ordem mais tradicional, contenha espaços de autoria. Mesmo na reprodução de códigos e condutas de uma dança de caráter clássico, é preciso encontrar, no contexto escolar, indícios de um ballet que se constitua enquanto enunciado-dançado, noção esta que pode contribuir para que o próprio entendimento de ensino de dança seja ressignificado ao alocar o aluno na posição de protagonista do evento comunicativo-artístico-educacional.

\section{Referências}

\section{POLÊM!CA $\mid$ LABORE}


AMORIM, M. Para uma filosofia do ato: "válido e inserido no contexto". In: BRAIT, Beth. (org.). Bakhtin: dialogismo e polifonia. São Paulo: Contexto, 2009.

2010 .

Cronotopo e exotopia. In: BRAIT, B. (Org.). Bakhtin: outros conceitos chave. São Paulo: Contexto,

BAKHTIN, M. Estética da criação verbal. São Paulo: Martins Fontes, 2003.

Para uma Filosofia do Ato Responsável. Tradução aos cuidados de Waldemir Miotello e Carlos Alberto Faraco. São Carlos: Ed. Pedro e João Editores, 2010.

BAKHTIN, M.; VOLOSHINOV, V. N. Marxismo e filosofia da linguagem: problemas fundamentais do método sociológico na ciência da linguagem. São Paulo: Hucitec, 2010.

BARROS, D. L. P. Contribuições de Bakhtin às teorias do texto e do discurso. In: FARACO, C. A.; TEZZA, C., CASTRO, G. Diálogos com Bakhtin. Curitiba: UFPR 2001.

Dialogismo, polifonia e enunciação. In: BARROS, D. P. \& FIORIN, J. L. (org.). Dialogismo, polifonia, intertextualidade. 2. ed. São Paulo: EDUSP, 2011. p.1-9.

BRAIT, B. Bakhtin e a natureza constitutivamente dialógica da linguagem. In: dialogismo e construção de sentido. Campinas: UNICAMP, 2005. (Org.). Bakhtin,

BRASIL. Ministério da educação. Secretaria de Educação Fundamental. Parâmetros Curriculares Nacionais: arte. Brasília, DF, 1998.

COSENTINO, E. Escola clássica do ballet. Porto Alegre: Globo, 1985.

LIMA, L. Dança como atividade básica: perspectiva para uma nova era. Revista Brasileira de Medicina do Esporte, São Paulo, v. 1, n. 3, p. 94-96, 1995.

MACHADO, I. Texto e gêneros: fronteiras. In: DIETZSCH, Mary. (Org) Espaços da Linguagem na Educação. São Paulo: Associação Editorial Humanitas, 2005.

MALANGA, E. B. Comunicação e balê. São Paulo: EDIMA, 1985.

MARQUES, I. Ensino da dança hoje: textos e contextos. São Paulo: Cortez, 1999.

Dança-Educação ou Dança e Educação? Dos contatos às relações. In: TOMAZZONI, A.; WOSNIAK, C.; MARINHO, N (Org.). Algumas perguntas sobre dança e educação. Joinville: Nova Letra, $2010 \mathrm{a}$.

Dança: arte e ensino. São Paulo: Digitexto, 2010b.

SCARPATTO, M. T. Dança educativa: um fato em escolas de São Paulo. Cadernos Cedes, ano XXI, n. 57 , 2001.

SETENTA, J. S. O fazer-dizer do corpo: dança e performatividade. Salvador: EDUFBA, 2008.

SOBRAL, A. Do dialogismo ao gênero: as bases do pensamento do Círculo de Bakhtin. Campinas, SP: Mercado de Letras, 2009.

STRAZZACAPPA, M. Dançando na Chuva... e no Chão de Cimento. In: FERREIRA, Sueli (Org.). O Ensino das Artes: Construindo Caminhos. Campinas, São Paulo: Papirus, 2001.

M. A tal "Dança Criativa": afinal, que dança não seria? In: TOMAZZONI, A; WOSNIAK, C.; MARINHO, N. (Org.). Algumas perguntas sobre dança e educação. Joinville: Nova Letra, 2010.

\section{POLÊM!CA $\mid$ LABORÉ}

Polêmica - Revista Eletrônica da Uerj - Rua São Francisco Xavier, 524, $1^{\circ}$ andar bloco D, sl.1001 • Tels.: +55 21 2334-4088/4087 • http://www.e-publicacoes.uerj.br/index.php/polemica/index http://www.labore.uerj.br • laboreuerj@yahoo.com.br 
Recebido em: 29/05/2016.

Aceito em: 20/10/2016.

\section{POLÊM!CA $\mid$ LABORE}

Polêmica - Revista Eletrônica da Uerj - Rua São Francisco Xavier, 524, $1^{\circ}$ andar bloco D, sl.1001 • Tels.: +55 21 2334-4088/4087 • http://www.e-publicacoes.uerj.br/index.php/polemica/index http://www.labore.uerj.br • laboreuerj@yahoo.com.br 